\title{
UNA PARTIDA DE ERUDICIÓN CON GALLARDO AL FONDO: LAS NOTAS INÉDITAS DE CAYETANO ALBERTO DE LA BARRERA A LA HISTORIA DE LA LITERATURA ESPAÑOLA DE GEORGE TICKNOR
}

\author{
BELÉN MOLINA Huete \\ Universidad de Málaga
}

- $n$ la notable colección de repertorios y obras generales que para consulta de libre acceso alberga la Sala Cervantes de nuestra Biblioteca Nacional - casi a ras de suelo y ceñido de cintas rojas, ciertamente algo disuasivas-, se halla un juego de cuatro volúmenes correspondientes a la Historia de la literatura española de G. Ticknor (sign. INV 860 Tic). Esta traducción del original en inglés de 1849 fue preparada, con adiciones y notas críticas, por Pascual de Gayangos y Enrique de Vedia, y fue publicada por la editorial madrileña de M. Rivadeneyra en los años 1851 (tomos I-II), 1854 (III) y 1856 (IV) ${ }^{1}$.

\footnotetext{
${ }^{1} \mathrm{Al}$ margen de los comentarios de Gayangos y Vedia, la versión española cuenta con correcciones y añadidos importantes que aportó el propio Ticknor y que no figuraban en la primitiva History of Spanish Literature (3 vols.), publicada simultáneamente en Nueva York (Harper and Brothers) y Londres (J. Murray). Destaca en este sentido el conjunto de apéndices con textos literarios poco conocidos que cierra el cuarto volumen.
} 
Nada de extraño guardaría su presencia si no fuera porque, haciendo honor al espíritu de la sala, se trata de un valioso ejemplar, único por la circunstancia particular que lo avala: una serie de notas manuscritas debidas a Cayetano Alberto de la Barrera. La figura de este insigne bibliófilo y erudito, a la luz de su papel como estudioso de la poesía del Siglo de Oro - faceta en la cual, como su maestro y modelo confesado B. J. Gallardo, representó una línea de trabajo mucho más efectiva y fecunda que la que terminó imponiéndoseviene siendo rescatada por J. Lara Garrido en sus últimas investigaciones². Precisamente, el hallazgo de estas notas de La Barrera, que nunca antes hemos visto citadas ni referenciadas, ha tenido lugar en el curso de rastreo, localización y acopio de sus materiales originales.

Cabe decir, de entrada, que los apuntes sobre la Historia de Ticknor procuran una doble ilustración de la obra. Por un lado, una ilustración ornativa, ya que conforme al estilo propio de su autor presentan una exquisita caligrafía y una presencia escrupulosamente acorde con la disposición tipográfica del libro. Como tendremos ocasión de comprobar, algunas de ellas carecen de firma, pero tanto la homogeneidad de letra como el peculiar sistema ortográfico que el erudito heredó de B. J. Gallardo -y que aquí queda simplificado y normalizado ${ }^{3}-$ no dejan lugar a dudas acerca de su autoría completa. Por otra parte, conforme al sentido de «ilustración» que marca los estudios literarios del momento - esto es, de esclarecimiento, glosa y comentario de las obras - las notas constituyen una cualificada fe de erratas que, más allá de remediar meros descuidos de impresión, enriquece sustancialmente no sólo el texto presentado por Ticknor sino también el adicionado por los traductores 4 .

Vistas globalmente, es cierto que estas notas de La Barrera apenas si representan una raya en el agua entre la inmensidad de datos ofrecidos por

\footnotetext{
2 Remitimos a J. Lara Garrido, «Para un capítulo de la historia recepcional de la poesía del Siglo de Oro: el inédito Cancionero de poetas varios españoles de los siglos XVI y XVII de Cayetano Alberto de la Barrera», en I Canzonieri di Lucrezia Borgia, Ferrara, en prensa. Así como al estudio que aparece en esta misma publicación con el título «Riesgo y ventura de un gran bibliógrafo, estudioso del Siglo de Oro. Nuevo perfil de Cayetano Alberto de la Barrera».

${ }_{3}^{3}$ Es preciso señalar que la indicación ordinal que aparece entre corchetes se debe a nosotros. Asimismo, con objeto de facilitar la intelección de las notas, cada una de ellas viene encabezada por una breve reconstrucción (en cursiva) de su contexto inmediato.

4 Por lo general, las notas que publicamos no tienen como fin la corrección de erratas de imprenta. Es por ello que no se sobreescriben las enmiendas que promueven los traductores desde sus particulares corrigenda, y se obvian numerosos fallos que afectan a la paginación general de la obra y a la que sirve de referencia para las notas de los adicionadores españoles. La comparación con el original hubiera procurado a La Barrera conocer que algunos de los datos equivocados que pasaron por error del hispanista no fueron más que erratas en la versión española no advertidas por los traductores (véanse como ejemplo las notas con fechas [8] y [67]) o descuidos en el traslado al español (cf. la rigurosa crítica al empleo de la expresión «salir a luz» de la nota [10]).
} 
Una partida de erudición con Gallardo al fondo: las notas inéditas de Cayetano Alberto de la Barrera a la Historia de la literatura española de G. Ticknor

Ticknor en la que fue la primera historia orgánica (por extensión temporal y por tratamiento homogéneo de todos los géneros) de la literatura española. Momentos en que el hispanista flaquea y el erudito emerge orgulloso con su escalpelo para dejar traslucir la minuciosidad de su lectura (adviértase que la mayor parte de sus comentarios se vuelcan en noticias dadas a pie de página), su superior competencia en determinadas materias y su rigor metodológico a la hora de enfrentarse a los estudios literarios. Así, se produce la denuncia sistemática por parte de La Barrera de imprecisiones que no hacen más que revelar la ligereza con que Ticknor abordó ciertos aspectos que resultaban primordiales para quien, con el referente diáfano de su maestro, pretendía continuar un modelo filológico muy concreto. Como Gallardo, desde la erudición y la fidelidad al documento, La Barrera acometía el rescate de una «descuidada historia literaria», muy lejana en sus planteamientos oficiales a su realidad positiva; falta, sin duda, de una detallada catalogación y descripción bio-bibliográfica de autores y obras que habría de tener como principal propósito el firme establecimiento de los textos, la consolidación de sus lecturas, y la valoración crítica de la manera más objetiva posible. Así pues, como afirma J. Lara Garrido en este mismo volumen:

\begin{abstract}
Bajo la inmensa mole de sus obras de erudición y el vasto aliento de su programa de trabajo hay bastante más que una compulsiva manía bibliofílica o el refugio de un misántropo. Late la idea coherente del destino final en una historia literaria de nueva planta, a que habían de servir la preparación de instrumentos biobibliográficos lo más exhaustivos y precisos posibles. Y consecuentemente, La Barrera supo asumir el voluntario renunciamiento de todo cuanto no condujese a la perfección de unas obras que sentarían los cimientos sobre los que otras generaciones debían levantar el monumento debido a la literatura española del Siglo de Oro.
\end{abstract}

De ahí las puestas en evidencia por parte de La Barrera de la confusión de autores que se da tanto en Ticknor (notas [19], [41]) como en los mismos traductores cuando pretendían matizar o corregir sus asertos (notas [18], [30]). Y de ahí también el hincapié sobre los deslices de índole bibliográfica (notas [6], [24]) y el afán por restituir la información que en este sentido no había manejado Ticknor. En muchas ocasiones, amén de aportar nuevos datos sobre el tema tratado, la intervención de La Barrera prueba que los argumentos de Ticknor que se censuran podían haber aparecido como correctos de haber promediado la consulta de obras pertinentes, y no sólo antiguas - las más frecuentadas por el erudito madrileño - sino también próximas a sus días (notas [2], [31], [32], [33], [38]). Aunque de modo fehaciente La Barrera había expresado su 
dedicación exclusiva al libro antiguo y su consecuente renuncia a la lectura de los modernos salvo la obra de Gallardo, sus comentarios demuestran el seguimiento de las ediciones más actuales de los clásicos medievales y áureos, lagunas en Ticknor que no siempre supieron suplir sus anotadores (notas [7], [9]). No faltarán, sin embargo, alardes propios de la vanidad bibliofílica que le lleva a marcar ciertas ausencias desde los libros raros que posee (notas [1], [11], [44], [63]).

Del celo textual y de su pericia para detectar obras mencionadas y no leídas - o al menos no esmeradamente - son buena muestra las notas respectivas [2], [39], [59] y [1], [34] o [16], esta última referida a los traductores. No son pocas tampoco las ocasiones en que La Barrera se ve en la obligación de avisar sobre las incongruencias que salpican la Historia de Ticknor, como la omisión de autores en su correspondiente apartado y su aparición posterior sin haber tratado de ellos previamente (notas [5], [35]); o, sobre todo, acerca de la ambigua postura de los traductores en relación con el famoso asunto del Buscapié atribuido a Cervantes (notas [28], [60], [62] y [68]). Hasta el punto de que la objetividad y la serenidad que caracterizaban el tono de estos apuntamientos se pierden sólo en estos casos y se revuelven en indignación ante el poco reconocimiento nacional de los trabajos debidos a Gallardo y a él mismo que daban por zanjado el debate acerca de la patraña urdida por Adolfo de Castro.

El elogio y el homenaje de La Barrera al gran modelo se hace consigna nuevamente aquí como en general sucedió en todas sus tareas. Gallardo, que también llenó de apostillas sus libros en un proceso de continuada revisión, era el «eminente bibliógrafo y filólogo» (nota [2]) cuya memoria era preciso reparar por su gran contribución a la nobleza de la historia literaria, recordando sus primicias (nota [5]) y rememorando sus interesantes opúsculos (nota [14]). Y no por ello dejando de mostrar sus desacuerdos cuando razones de peso le conducían a tomar una postura contraria a la del maestro (nota [2]).

Nada podemos establecer de manera definitiva acerca de las fechas en que fueron redactados estos apuntes. Auxiliándonos con los hitos que facilitan las obras mencionadas como bibliografía, y que pueden intervenir en la datación aproximada de cada nota concreta, se nos dibuja un abanico general que abarca desde la aparición en cada caso de cada uno de los volúmenes traducidos $(1851,1854,1856)$ hasta justo el año en que falleció don Cayetano, ya que queda mencionado el «Catálogo grande» de P. Salvá que se publicó en ese año de 1872 (nota [47]). La posibilidad de distinguir diversos estadios de elaboración, como parece corroborarse en los trabajos no conclusos de La Barrera, nos la proporciona la nota [7]. Por otro lado, la fuerte conexión existente entre gran parte de los comentarios y el contenido volcado en su 
Una partida de erudición con Gallardo al fondo: las notas inéditas de Cayetano Alberto de la Barrera a la Historia de la literatura española de G. Ticknor

Catálogo bibliográfico y biográfico del teatro antiguo español nos permite determinar que muchos de los datos consignados se conocían ya al menos en 1860. De no sobrevenirle la muerte, tal vez La Barrera hubiera tenido ocasión de aumentar sus aportaciones, completar las notas inacabadas (nota [42]) y tal vez de rectificar allí donde el error minó su escrupulosidad (nota [45]).

Convenimos con J. Lara Garrido en que Cayetano Alberto de la Barrera fue el único discípulo de Gallardo. El único continuador del proyecto de una historia mayor de la literatura española, fruto del convencimiento de la superioridad de nuestra creación, al que sin embargo los intelectuales del país no habían sabido dar voz ni proyección. El mercado editorial quedaba reñido con trabajos cabales y de gran alcance como los catalográficos, más ansioso de conjuntos que de minuciosidades, más condescendiente con la amenidad de la hipótesis que con el rigor del dato interpretado. Hubo de ser un extranjero quien viniera a dar forma primera a este propósito, con una más que notable preparación y conocimientos en la materia, pero con inevitables carencias y falta de solidez en la arquitectura y en los detalles. Y arropado, además, por dos grandes nombres de la filología institucional, ante los que no sin ironía La Barrera se decía un quidam (nota [60]), un cualquiera que, sin embargo, no vaciló en censurar sus faltas. Por ello, puede entenderse con naturalidad que esta Historia de la literatura española «florida y floreada», como la calificara el propio Gallardo, ofrezca en don Cayetano el indefinido perfil de una recepción confusa. De un lado, el asentimiento; por otro, el rechazo. La aceptación general del trazado y de las cuestiones de base apenas quedan dañadas por ciertos alejamientos en aspectos muy puntuales de crítica (notas [3], [21]). La desestimación, sin embargo, queda implícita en las correcciones que, aun en lo mínimo, denuncian las insuficiencias bibliográficas de la obra y el desconocimiento tanto del autor como de los traductores del amplio espectro de la poesía áurea (notas [38], [49]). Por último, el reto a seguir avanzando en su riguroso proyecto nos lo sirve el vaciado breve e intermitente de cuanto en sus terrenos más transitados (teatro antiguo español, Lope, Cervantes, poetas menores del Siglo de Oro, bibliografía...) vio preciso completar.

En definitiva, estas breves acotaciones, pulcras aun en su carácter de marginalia, no son sino una muestra más de esa labor suya de «anotador y renotador» de obras mayores, ajenas o propias (ver notas [2], [39], [47]), tan dispersa en sus resultados pero tan unitaria en intención. Con ellas ofrecemos un interesante documento para la historiografía literaria, en una época en que la recepción crítica, aun en notaciones de gabinete, tuvo mucho que decir, tanto o más que los libros sobre los que se podía corregir, anotar o modificar. Jugosas noticias en muchos casos que, ya nacieran como íntimo goce erudito o como 
Belén Molina Huete

arma crítica con vocación de expresión pública, se reconcilian ahora con su destino en el inédito lector.

\section{TOMO I}

[1]

Cap. X, nota 15 , p. 210

Entre las obras teatrales que tomaron como tema la hazaña de Hernán Pérez del Pulgar recogida en las crónicas de la conquista de Granada, Ticknor añade que la más antigua se debe a Lope de Vega y lleva por título Cerco de Santa Fe, pero apunta que la más representada es la anónima titulada El triunfo del Ave María, de tiempos de Felipe IV.

Ni esta comedia, ni la de Lope se refieren a la hazaña de Pérez del Pulgar, sino al combate de Garcilaso de la Vega con el moro Tarfe: hecho que está muy lejos de hallarse comprobado. (Véase el Catálogo de la Real Armería, por Martínez del Romero, 1849). Yo he tenido el gusto de encontrar, y poseo, la primitiva comedia de Lope sobre este asunto, inédita y que se creía perdida. ${ }^{5}$

La. B.

\footnotetext{
${ }^{5}$ En efecto, así lo hace explícito C. A. de la Barrera en su Catálogo bibliográfico y biográfico del teatro antiguo español: desde sus orígenes hasta mediados del siglo XVIII (Rivadeneyra, Madrid, 1860), bajo el título de Garcilaso de la Vega (Los hechos de Garcilaso de la Vega y Moro Tarfe). Igualmente, lo había consignado de su propia letra en el encabezamiento del manuscrito dramático, que vio años después M. Menéndez Pelayo en la Biblioteca Nacional: «La Comedia de los hechos de Garcilaso de la Vega y Moro Tarfe, compuesta por Lope de Vega, y por él mencionada con el simple título de Garcilaso de la Vega, es completamente inédita: la gloria de su descubrimiento me pertenece. Casi puede decirse que ni aun constaba como perdida; puesto que enlazándose también el argumento de la titulada El cerco de Santa Fe, incluida en la Primera parte de Comedias del mismo autor, con el dudoso hecho de ese tal Garcilaso, generalmente se calculaba que debían de ser una misma pieza. Pero sólo tienen de común el asedio de la ciudad o el triunfo del Ave María» [M. Menéndez Pelayo, Estudios sobre el teatro de Lope de Vega. V. Crónicas y leyendas dramáticas españolas (cont.), en Obras Completas, ed. de E. Sánchez Reyes, Santander-CSIC, 1949, pp. 227-236, esp. 227].

Era creencia de Menéndez Pelayo que este Garcilaso de la Vega fuera la comedia más antigua conocida de Lope, ya que respondía a la caracterización de sus primeros modos teatrales y carecía de adaptación para la imprenta. A propósito del Cerco de Santa Fe, que ya aparecía en la primera lista de El peregrino en su patria (1604), el polígrafo santanderino redunda en los planteamientos ya avanzados por La Barrera y explicita que debe considerarse una obra muy distinta de la anterior aunque trate similar asunto (Estudios, pp. 237-248).

Sobre El triunfo del Ave María, La Barrera adscribió esta obra con interrogante al casi desconocido autor de mediados del siglo XVII llamado P. Rosete Niño (véase su Catálogo, pp. 344-346, esp. 346).
} 
Una partida de erudición con Gallardo al fondo: las notas inéditas de Cayetano Alberto de la Barrera a la Historia de la literatura española de G. Ticknor

\begin{abstract}
Al hablar del Amadís de Gaula como libro inicial del género caballeresco, Ticknor da como argumento de antigüedad la cita de Pero López de Ayala (†1407) en su Rimado de Palacio: "Plégome otrosi oir muchas vegadas / Libros de devanéos é mentiras probadas, / Amadis é Lanzarontes, é burlas á sacadas, / En que perdi mi tiempo á muy malas jornadas».
\end{abstract}

El eminente bibliógrafo y filólogo D. B. J. Gallardo, en su precioso artículo sobre López de Ayala («Cartas Españolas», Revista Española, 1832) opina con mucho acierto que este pasaje del Rimado del Palacio se halla viciado. El códice más antiguo de esta obra es de fines del siglo XV: su copiante hubo de sustituir Amadís x Tristán. Con Tristán consta el verso. Tristán y Lanzarote, héroes caballerescos de historia y origen análogos, van frecuentemente citados juntos. Pero aunque sobre este particular estoy de acuerdo con Gallardo, no así respecto a la antigüedad del Amadís, si su opinión acerca de ella era la que transluce en el expr[esado] artículo, donde alude a documentos que p[ara] su apoyo poseía y reservaba. Últimam[ente] el Sr. Gayangos ha ilustrado la nueva edición del Amadís (tomo XL de la Bibl. de AA. Esp[añoles], 1857) con un «Discurso» en que trata la cuestión detenida y eruditamente: «Discurso» que en mi ejemplar he anotado con extensión y prolijidad. ${ }^{6} \quad$ La. B.

En su relación acerca de La Celestina, Ticknor acaba proponiendo la unidad en la autoría basándose en la homogeneidad de estilo en la obra, y en nota habla de quienes siguen su misma opinión (Blanco White, Mr. Germond de Lavigne, Moratín...) así como de aquellos que son partidarios de reconocer un doble autor (Valdés, Lampillas).

Gallardo me indicó más de una vez que él no encontraba diferencia entre el estilo del acto $1^{\circ}$ y el de los restantes. No participo yo de esta

\footnotetext{
${ }^{6}$ El referido trabajo de B. J. Gallardo lleva por título «Trovadores antiguos del gran canciller Pero López de Ayala y su famoso Rimado de Palacio. Correspondencia del Bachiller de Fórnoles con el Bachiller Zíagar». Se trata de un conjunto de tres artículos. Los dos primeros se editaron en Cartas españolas, Madrid, 1832, VI, pp. 209-214. La Revista de España, que sustituyó a la publicación anterior, dio a luz al tercero en los números 10 y 11 de 1832. Cf. A. Rodríguez Moñino, Don Bartolomé José Gallardo (1776-1852), Sancha, Madrid, 1955, p. 128. Para la correspondencia con Tomás García Luna («Zíagar»), véase A. Pérez Vidal, Bartolomé J. Gallardo [Sátira, pensamiento y política], Editora Regional de Extremadura, 1999, pp. 352-353.
} 
opinión. Acerca de Cota veánse las curiosas noticias que dan los ilustradores del Cancionero de Baena. Sobre Rojas (?) aquí en las «Adiciones»: pág. 545, y con más seguridad en la 571; y en el citado Cancionero. ${ }^{7}$

\begin{abstract}
Al tratar de la saga de imitaciones de La Celestina, sale a flor el nombre de esta obra «alabada en demasía por Quevedo». Ticknor la atribuye a Ferreira de Vasconcellos, manifestando desconocer las razones que llevaron a Ballesteros Saavedra a considerarla anónima en su traducción de 1631 o de Lobo por autores como Quevedo. Según Ticknor el portugués tan sólo imprimió en 1613 una reedición del original.
\end{abstract}

Atribúyese la Eufrosina al portugués Jorge Ferreira de Vasconcellos. Salió a luz por primera vez en Coimbra, 1560, anónima y se reimprimió en Évora, 1566. Franc[isco] Rodríguez Lobo, excelente poeta, natural de Leiria, la hizo imprimir de nuevo en Lisboa: 1616. De la traducción castellana hay otra edición de Madrid, 1735, muy curiosa, hecha por Nasarre, que se ocultó en ella bajo un extraño seudónimo. Las primitivas ediciones fueron prohibidas: con las supresiones de Lobo se permitió ya la de $1616 .^{8}$

\footnotetext{
7 Con toda probabilidad se refiere La Barrera a la edición por vez primera de El cancionero de Juan Alfonso de Baena (siglo XV) anotado y comentado por Eugenio de Ochoa y Pedro José de Pidal (Rivadeneyra, Madrid, 1851). El artículo que dedica el Catálogo al Bachiller Fernando de Rojas recoge el acuerdo de La Barrera en identificar a Rojas con uno de los jóvenes poetas del Cancionero de Baena con ese nombre, tal como habían propuesto Gayangos y Vedia en sus "Adiciones»; discrepa de ellos, sin embargo, cuando en otro lugar afirman ser el mismo Rojas que localizan como autor de un Tractado de la fascinación fechado en 1456. Por otra parte, los argumentos presentados parecen indicar que La Barrera se mostraba partidario de dos autores para $\mathrm{La}$ Celestina: Rojas y, muy probablemente, Cota. No lo entendió así J. Fitzmaurice Kelly, quien en carta a M. Menéndez Pelayo, lo integraba junto a los críticos que apostaban por la unidad de la obra (M. Menéndez Pelayo, Epistolario, XII, ed. de M. Revuelta Sañudo, Madrid, 1986, carta $n^{\circ}$ 552).

8 Bajo la entrada de J. Ferreira de Vasconcellos, el Catálogo de La Barrera (pp. 155-156) recoge exhaustivamente una secuencia editorial de la Eufrosina que queda replanteada, sin embargo, en la edición crítica de esta novela dialogada a cargo de E. Asensio (CSIC, Madrid, 1951). Nada queda indicado aquí acerca de la atribución a Blas Antonio Nasarre de la reimpresión dieciochesca de la obra, con lo que el recordatorio del dato puede resultar novedoso. El seudónimo empleado por Nasarre fue el de don Domingo Terruño Quexilloso (cf. Catálogo, p. 156).
} 
Una partida de erudición con Gallardo al fondo: las notas inéditas de Cayetano Alberto de la Barrera a la Historia de la literatura española de G. Ticknor

Ante la tajante afirmación de Ticknor de que antes de 1517 no existe en España ningún continuador de la obra de Juan del Encina o de Gil Vicente más allá de los escarceos del Comendador Escrivá y Francisco de Villalobos.

Aquí ignora Ticknor la existencia de Lucas Fernández y de sus Farsas impresas en 1514, y, jcosa singular!, en el tomo $2^{\circ}$ (pág. 379) las conoce y menciona sin expresar el origen de la noticia. Esto no es sino afectar repetidamente desprecio a D. B. J. Gallardo, a quien es debida, y pugnar porque su memoria y sus inestimables tareas queden olvidadas y oscurecidas. ¡Vano y ridículo empeño! Gallardo logrará reparación cumplida: sus escritos se guardan y aprecian como joyas; y en esta misma obra, a despecho del autor, le hacen justicia los traductores. Véanse las págs. 506, 509, 576 de este volumen. ${ }^{9}$

La. B.

\footnotetext{
${ }_{9}^{9}$ Es cierto que en la p. 379 del tomo II de esta Historia de la literatura española el hispanista reserva una breve nota (n. 59) a Lucas Fernández como autor de obras de églogas y coloquios pastoriles que continúa la labor de Juan del Encina y cuya tradición rescata como antigua el teatro de Lope, pero reconoce Ticknor no haber visto el libro de Farsas y églogas al modo y estilo pastoril y castellano. La restauración de Gallardo a cargo de los traductores supone la remisión en las páginas indicadas a estudios de insigne valor para el avance en los conocimientos literarios. En la p. 506 proponen la lectura de los artículos de Gallardo recogidos en el tomo VI de las Cartas españolas y los escritos bajo seudónimo para completar la figura del Canciller Pero López de Ayala que fueron referidos con ocasión del apunte [2] de La Barrera (véase la n. 6 de este trabajo). La p. 509 reivindica la carta de Gallardo en el número 3 de la revista Antología española titulado «Del asonante, su naturaleza y exquisito mecanismo, misterio rítmico no penetrado por nadie, hasta que lo descubrió el autor de la siguiente» (de este artículo hay mención por La Barrera más adelante, véase apunte [14] y la nota al pie correspondiente). Por último, en el apartado final de «Addenda et corrigenda» (p. 576) los traductores sugieren añadir a la nota 14 del cap. XIV, p. 296, donde se está tratando de Juan del Encina, que B. J. Gallardo descubrió en el número 4 de Criticón (1836, pp. 26-35) la nueva figura dramática de Lucas Fernández, discípulo e imitador de Juan del Encina y anterior a Gil Vicente y Torres Naharro. Se describen también sus Farsas de 1514 y se da noticia de la edición parcial de su obra en el número 5 de la misma publicación. Una frase valorativa da indicio del seguimiento de Gallardo: «Lástima es por cierto que el distinguido escritor a quien debemos ésta y otras noticias, a cual más peregrina, de nuestra literatura poética y dramática, no nos haya hasta ahora dado sino muy escasos frutos de su erudición e ingenio. Véase también su artículo sobre el asonante, en el núm. 3 de la Antología española». El volumen II del Ensayo de una biblioteca española de libros raros y curiosos (1856), amén de la descripción de las Farsas y églogas, incorpora por iniciativa de los colectores Sancho Rayón y Zarco del Valle, dos nuevas piezas del libro que perteneciera a Gallardo y después al Duque de Osuna, y que completaban los anuncios de los números de Criticón ya citados (cols. 1019-1052). Se da asimismo el aviso de que Manuel Cañete acometería la edición completa de la obra.

La Barrera dedicó a Lucas Fernández las pp. 151-152 de su Catálogo, donde, como aquí, fielmente atribuye a Gallardo el descubrimiento de este autor.
} 
Belén Molina Huete

[6]

Cap. XVII, p. 357

\begin{abstract}
El ocaso de la literatura provenzal en España se constata según Ticknor con la celebración en Valencia de un certamen en honor de Nuestra Señora (1474) cuyos poemas se imprimieron en tal año por Bernardo Fenollar "siendo este el primer libro que se imprimió en España».
\end{abstract}

El primer libro impreso en España lo fue en Barcelona, año de 1468, por Juan Gherling, alemán, a costa de Guillermo Ros. Es un opúsculo gramatical de 50 hojas en $8^{\circ}$, compuesto por Bartolomé Mates; su epígrafe: Pro condendis orationibus juxta grammaticas leges Litteratissimi auctoris Bartholomei Mates libellus exorditur. Hallóle en la librería del Convento de Trinitarios de Vich, en 1833, el P. Fr. Pedro de la Concepción (Véase la pág. 572). ${ }^{10}$

\begin{abstract}
Acerca de la obra del marqués de Villena, poco meritoria en general, Ticknor hace más hincapié en sus traducciones perdidas. Tan sólo de la Eneida virgiliana ha quedado mayor rastro. Al final de la nota correspondiente, Ticknor sugiere: «En la Biblioteca Real de París hay una traducción manuscrita de los nueve últimos libros de la Eneida de Virgilio, hecha por un tal Juan de Villena, que se intitula criado de D. Íñigo López de Mendoza. [...] Sería, por cierto, muy curioso el averiguar qué relación tienen entre sí estas dos traducciones de Virgilio».
\end{abstract}

Esta nota de Ticknor motivó la publicación en el Semanario pintoresco Español ( $\mathrm{n}^{\circ} 44$ de 1852) de un razonado artículo, sin firma, en el cual, puestas de manifiesto las descripciones que de los códices han hecho respectivamente Pellicer y Ochoa, se hace ver la conexión y analogía que tienen estos dos fragmentos. A mi juicio, constituyen entre ambos

\footnotetext{
10 Nos consta que la impresión de las Obres e trobes en lahors de la Verge Maria (1414) indicado por Ticknor como primer libro hecho en España corrió a cargo de Lambert Palmart en Valencia. En la p. 576 los traductores desautorizan al Padre Méndez en su Tipografía española, que es el referente usado por Ticknor para dar el dato, y dan lugar de privilegio a la obra mencionada por La Barrera: «[...] consta por documentos irrefragables que el primer libro salido de las prensas españolas es el opúsculo gramático de Bartolomé Mates, que se imprimió en Barcelona por Juan Gherling, alemán, a 9 de octubre del año 1468. (Véase la disertación publicada en Vich por D. Jaime Ripio, Vilamajor, 1833, $4^{\circ}$ )». Hoy en día, sin embargo, el honor correspondiente lo ostenta el llamado Sinodal de Aguilafuente, impreso al parecer en Segovia, por el alemán Juan Párix en 1472. La fecha del libro de Mates es en realidad 1488.
} 
Una partida de erudición con Gallardo al fondo: las notas inéditas de Cayetano Alberto de la Barrera a la Historia de la literatura española de G. Ticknor

la traducción completa de la Eneida hecha por D. Enrique de Aragón. Indudablemente el de París es una copia ejecutada por Juan de Villena (coincidencia casual de nombres) para su señor el Marqués de Santillana. (Con posterioridad ha resuelto completam[ente] la duda el Sr. D. J. Amador de los Ríos cotejando ambos códices con auxilio del Sr. Conde de Circourt. El de nuestra Bibl. Nac[ional], en 2 tomos (M-16-17) contiene los seis primeros libros: el de la Imp[erial] de París (1812) los nueve últimos: existe pues completa la traducción. (Véanse las ilustr[aciones] de d[icho] Sr. Ríos a su colección de las Obras del Marq[ués] de Santillana: págs. 643-44).11

[8] Cap. XIX, p. 391

El año de fallecimiento del rey Juan II aparece como 1545. $1454^{12}$

Dadas las referencias bibliográficas para seguir la figura del Marqués de Santillana.

Poco después de impreso este tomo de Ticknor, ha publicado el Sr. D. José Amador de los Ríos su preciosísima colección de las Obras del Marqués de Santillana... compiladas de los códices originales, e ilustradas con la Vida del Autor, notas y comentarios... (Madrid, 1852, fol.), a expensas del Sr. Duque de Osuna, Marqués de Santillana, D. Mariano Téllez Girón. Es una de las publicaciones que más honor hacen a nuestra época.

$$
\begin{aligned}
& \text { Cap. XIX, p. } 406 \\
& \text { Comentario a la siguiente frase de Ticknor referida a Juan de Mena: «Las obras } \\
& \text { de Juan de Mena gozaron evidentemente de los primeros favores del Rey y de su } \\
& \text { corte, desde el momento mismo que salieron a luz». }
\end{aligned}
$$

La frase salir a luz sólo se aplica en bibliografía a la publicación por medio de la imprenta. De las obras de Mena, la primera que salió a luz fue el Laberinto, en

11 Véase el apunte [9].

12 Obviamente se trata de un error de la versión española, ya que la fecha que da Ticknor en el original en inglés es la correcta. 
Sevilla, año 1496. La portada de esta rarísima edición lleva únicamente, bajo un grabado en madera que representa al autor ofreciendo su libro al Rey D. Juan II, el siguiente título: Las CCC de Juan de Mena. El colofón, al fin, dice: «Acabanse las CCC de Mena imprimidas en Sevilla a instancia y espensas de Juan Thomas Farario de Lumelo del Condado de Pavia en el anno de Mill CCCCXCVI a XII de Enero». $4^{\circ}$ de 44 fols. l. g. ${ }^{13}$

$$
\text { Cap. XXI, nota 15, p. } 441
$$

Tras la exposición en nota de la bibliografía correspondiente al poema de Juan de Padilla El Cartujano (1518) titulado Los doce triunfos de los doce apóstoles.

Otro poema de la misma estrofa, aunque menos digno de aprecio que los del $\mathrm{P}$. Padilla, se publicó en su tiempo con el siguiente título:

Comienza el libro de la celestial jerarquia y infernal labirinto metrificado en metro castellano en verso heroico y grave por un religioso de la orden de los minimos dirigido al ilustre y muy magnífico señor Don Juan de la Cerda duque de Medinaceli Conde del puerto de Sancta María, etc.

El ejemplar que poseo está de antiguo encuadernado con los Doce Triunphos. En la «Dedicat[oria]» hace el autor mención de Padilla diciendo: «Aun en $\mathrm{n}[\mathrm{ues}] \mathrm{tros}$ tiempos vive un devoto religioso cartuxano... que escribió el vita xpi...», etc. Consta el poema, cuyo asunto declara expresamente el título, de 479 octavas de arte mayor.

Descripción de Ticknor de una reimpresión del Cancionero General hecha en Londres en 1841 con adiciones al original sin nombrar el responsable del «prólogo bien escrito» ni del «corto aunque erudito glosario».

Fue el editor e ilustrador de esta reimpresión el erudito D. Luis de Usoz y Río. ${ }^{14}$

\footnotetext{
${ }^{13}$ La desafortunada expresión es responsabilidad de los traductores. El original reza: «The works of Juan de Mena evidently enjoyed the sunshine of court favour from their first appearance» (I, p. 348).

14 Cf. Cancionero de obras de burlas provocantes a risa [Basado en la edición original (Valencia, 1519), con las composiciones suprimidas del Cancionero General de Hernando del Castillo y las adiciones y advertencias de Luis de Usoz y Río (Londres, 1841-1843)], ed. de P. Jauralde Pou y J. A. Bellón Cazabán, Akal, Madrid, 1974.
} 
Una partida de erudición con Gallardo al fondo: las notas inéditas de Cayetano Alberto de la Barrera a la Historia de la literatura española de G. Ticknor

\section{NOTAS Y ADICIONES DE LOS TRADUCTORES}

[13]

$$
\begin{aligned}
& \text { Cap. I, nota 5, p. } 14 \text { (p. 493) } \\
& \text { Sobre los orígenes de la poesía castellana los traductores ven oportuno trasladar } \\
& \text { algunas notas manuscritas del Sr. Floranes Robles sobre la poesía anterior al } \\
& \text { XV. En el apunte referido al documento que en } 1236 \text { hace alusión al } \\
& \text { repartimiento de Sevilla se menciona entre otros a un «Pedro Abad, chantre o } \\
& \text { cantor, el cual pudiera muy bien ser el autor o el copiante del poema del Cid, } \\
& \text { puesto que si era conocido como trovador o juglar, pudo muy bien componer el } \\
& \text { cantar de gesta del héroe castellano». }
\end{aligned}
$$

Para ser así, dado por evidente que la fecha del códice sea de la era 1345 (año 1307) y suponiendo que a la del repartimiento de Sevilla contase Pedro Abad sólo 24 años, debía tener ya 95 cuando escribió el poema o ejecutó su copia; cosa, en verdad, bien improbable.

$$
\begin{aligned}
& \text { Cap. VI, nota 13, p. } 119 \text { (p. 509) } \\
& \text { En la remisión que hacen los traductores acerca del asonante a una carta de B. J. } \\
& \text { Gallardo en el } n^{0} 3 \text { de la Antología. }
\end{aligned}
$$

Antología Española. Revista de Ciencia, Literatura, Bellas Artes y Crítica, de El Siglo, Madrid, 1848. La carta va dirigida a D. Miguel José Moreno, ingenio sevillano, a la sazón que éste escribía su traducción de la Iliada (por septiembre de 1826). Es artículo de singular mérito, y contiene exquisitas noticias literarias. ${ }^{15}$

$$
\text { Cap. VIII, nota 23, p. } 173 \text { (p. 516) }
$$

\footnotetext{
15 Previo a este famoso artículo sobre el asonante existió uno publicado con el seudónimo de J. T. Gramblalla en el n ${ }^{\circ} 80$ de la Revista española, Madrid, 1833 titulado «Prosodia del asonante y su uso especial en la rítmica española». Este primer trabajo tuvo cierto eco como demuestra la contestación a una crítica del mismo que publicó tal revista en el $n^{\circ} 93$ de ese año. Y tuvo fama además, ya que volvió a imprimirse en El Vapor de Barcelona, $\mathrm{n}^{\circ}$ 82, en septiembre de 1833.

Respecto al artículo en cuestión, «Del asonante, su naturaleza y exquisito mecanismo, misterio rítmico no penetrado por nadie, hasta que lo descubrió el autor de la siguiente carta», fue nuevamente publicado en la Revista mensual de filosofía, literatura y ciencias de Sevilla, V, 1873. Modernamente ha sido reproducido por A. Rodríguez Moñino (op. cit., $\mathrm{n}^{\mathrm{o}}$ 116, pp. 208-223), por quien seguimos los datos correspondientes a este trabajo. Véase también A. Pérez Vidal, op. cit., p. 354.

Las «exquisitas noticias literarias» refieren sin duda los abortados proyectos editoriales que B. J. Gallardo expone a colación de sus obras perdidas el aciago día sevillano de San Antonio de 1823.
} 


\begin{abstract}
Manifiestan los traductores haber consultado el manuscrito de la Biblioteca Nacional en que se encuentra el Compendio de la Crónica General de Alfonso el Sabio atribuida a D. Juan Manuel sin que hallen argumentos a favor de la conjetura de Ticknor expresada en el texto. El hispanista suponía que el pasaje concreto referido al traslado del sepulcro de Rodrigo Díaz de Vivar recogido en la Crónica del Cid, y en el cual quedaba mencionado San Fernando, no sólo demostraba que el relato era posterior y dependiente de la Crónica General de Alfonso X el Sabio, sino que inducía a pensar que había sido añadido posteriormente teniendo a vista algún otro texto que albergara una historia conjunta de San Fernando y el Cid.
\end{abstract}

Para completar el artículo de las Crónicas sería necesario añadir aquí todas las noticias que de las m[anuscritas] existentes en la Bibli[oteca] del D[uque] de Osuna da el Sr. D. J. A. de los Ríos en sus ilustrac[iones] a las Obras del M[arqués] de Santillana (8, págs. 605-7 de éstas).

$$
\text { Cap. XIX, nota 54, p. } 412 \text { (p. 546) }
$$

En la ampliación sobre Juan de Mena, los traductores hablan acerca de las 24 coplas añadidas al Laberinto de Fortuna, impresas según ellos por primera vez en Sevilla, 1517.

Están equivocados los Sres. traductores. Las XXIIII coplas se hallan ya en la edición de Las CCC impresa en Zaragoza por George Coci, año de 1509: «agora» dice «nuevamente añadidas».

En la disquisición acerca de la identidad del "Cartagena» presente en el Cancionero General, los traductores atribuyen a Mayans (Retórica, II, pp. 230, 235) su alianza con un tal «"Pedro", sin dar más noticias de él».

Fernando de Herrera cita y elogia en sus Anotaciones a las Obras de Garcilaso al poeta Pedro de Cartagena. 
Una partida de erudición con Gallardo al fondo: las notas inéditas de Cayetano Alberto de la Barrera a la Historia de la literatura española de G. Ticknor

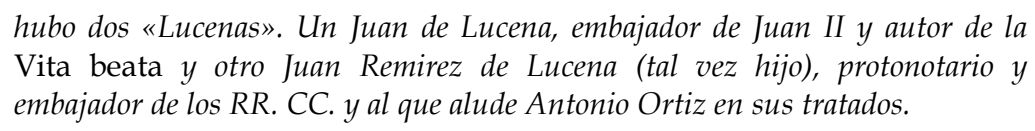

Aquí dan por seguro los traductores que el Lucena embajador y consejero de D. Juan $2^{\circ}$, fue distinto del Lucena, protonotario y embajador de los Reyes Católicos; y, bajo este supuesto, que el primero de ellos fue el autor de la Vita Beata. Este último extremo de su aserción es equivocado. El diálogo De Vita Beata es la obra de Juan Remirez de Lucena el protonotario y embajador de los Reyes Isabel y Fernando; el autor de la «atrevida y célebre Carta a los dichos Rey y Reina, exhortándoles a que les fuesen a la mano a los Inquisidores en su rigor», escrito que dio ocasión a la fanática censura del Dr. Ortiz, y finalmente el autor de «otra Carta al Notario regio secreto de los mismos Reyes* alentándole al estudio del Latín»; la cual existe m[anuscrita] en la Biblioteca Colombina. (Gallardo: El Criticón, $\mathrm{n}^{\circ}$ 5, donde inserta de esta última curiosísimos pasajes). En cuanto a si el Lucena de D. Juan $2^{\circ}$ fue persona diversa, nada podemos afirmar: sólo advertiremos que el escritor pudo muy bien servir en uno y otro Reinado.

* Fernand Álvarez Zapata.

\section{TOMO II}

[19]

Cap. V, p. 96

Entre los autores de diálogo moral, Ticknor menciona en último término a Pedro de Urrea, «uno de los oficiales más queridos del emperador Carlos V...».

Aquí confunde Ticknor a D. Jerónimo Jiménez de Urrea con su pariente D. Pedro Manuel de Urrea, autor del Cancionero que lleva su nombre, impreso en Logroño, año de 1513.

[20]

Cap. VII, nota 45, p. 137

Corrección de la fecha de impresión valenciana del Deleitoso de Lope de Rueda que Ticknor confiesa no haber podido ver. La versión española consigna 1577.

156716

${ }^{16}$ El original de 1849 marca en este caso también 1577 (II, p. 10). 
Sobre la interpretación literal que Ticknor hace de El Quijote siguiendo los propósitos indicados por el propio Cervantes: «destruir el favor y autoridad que gozaban los libros de caballerías».

Cervantes no podía manifestar explícitamente el fin elevado y transcendental de su libro; pero en las «Décimas de Urganda» supo indicarle con destreza y cautela. Mr. Ticknor, Salvá y algunos otros han juzgado harto mezquinamente la grande obra en que bajo el velo de una censura del exagerado y general gusto literario-caballeresco, se encierra la más atrevida y filosófica del espíritu y los abusos del siglo en que se escribía y de tiempos muy anteriores.

La. B.

Junto a la plena conciencia de genialidad de Cervantes, plantea Ticknor las incongruencias y anacronismos que revela su gran obra. El primero, hacer pensar que Don Quijote vivió en una edad muy alejada de la de su autor y que fue un escritor árabe el narrador de su historia siendo que en otros momentos se hace contemporáneo a su creador. La nota apunta a las explicaciones que algunos eruditos daban al uso del nombre Cide Hamete Benengeli por parte de Cervantes, quien habría acudido a su conocimiento del árabe para exponer un nombre simbólico. Ticknor no acaba de aceptar la idea al considerarlo impropio de los usos y conocimientos de idiomas cervantinos.

Cide Hamete Benengeli es un anagrama imperfecto de Miguel de Cervantes (= Migel de Cebante). Este ilustre ingenio sabía sin duda del árabe lo muy bastante para formar ese nombre, cuya más probable significación es la otra de: 'hijo del ciervo' o 'cervanteño' (= Ben Iggeli), indicada por el mismo Conde.

La. B.

El ingente volumen de comedias escritas por Lope de Vega lleva a Ticknor a hacer una breve relación de los datos sobre su número. El primero que indica - 319 afirma tomarlo de la lista del propio Lope en El peregrino en su patria (1603). 
Una partida de erudición con Gallardo al fondo: las notas inéditas de Cayetano Alberto de la Barrera a la Historia de la literatura española de G. Ticknor

No son más de 218 títulos. En la edición de Madrid (1618) añadió otros $122 .{ }^{17}$

En la nota bibliográfica sobre La estrella de Sevilla Ticknor da fe de su conocimiento en el teatro español al margen de sus ediciones norteamericanas, y como muestra recuerda su reimpresión en Madrid y en Londres con el título de Sancho Ortiz de las Roelas.

La que lleva ese título no es reimpresión sino refundición de La Estrella de Sevilla hecha por D. Cándido María Trigueros. ${ }^{18}$

Entre los continuadores de Lope cuya fama fue reconocida en su época aunque ignorados en el momento de escribirse esta Historia Ticknor rescata el nombre de Luis Belmonte, autor de dos obras señaladas: Renegado de Valladolid y Dios es la mejor defensa.

El mejor tutor es Dios: es su verdadero título.

Otro de ellos es Andrés Gil Enríquez, autor de la comedia titulada por Ticknor La red, la banda y el cuadro.

17 En el «Suplemento a las notas» del tomo IV de esta Historia de Ticknor los traductores hacen corrección (p. 436) de este pasaje en los siguientes términos: «Cap. XV, p. 314. - Hay equivocación en el número de comedias que Lope anunció ya como suyas en 1603, pues en lugar de 341, como dice el texto, habrá de leerse 219; si bien él mismo se contradice, pues en el prólogo al Peregrino, 1603, dice que son 230, y en algunas ediciones posteriores, y principalmente en las de 1605, que sirvió para la reimpresión de sus Obras sueltas, t. IV, se dice terminantemente que fueron 38». Adviértase también el error de Gayangos y Vedia al indicar la cifra ofrecida por Ticknor en el cuerpo de texto.

18 Trigueros editó arreglada la tragedia de Lope en Madrid, Sancha, 1804. Una nueva edición de este Sancho Ortiz de las Roelas, enmendada por J. E. Hartzenbusch, apareció en 1863. Según el Catálogo de La Barrera - que sigue en este punto informaciones del propio HartzenbuschCándido $\mathrm{M}^{\mathrm{a}}$ Trigueros fue el refundidor de la obra de Calderón El sacrificio de Ifigenia cuya segunda parte se atribuía a Cañizares (p. 70). 
El lazo, banda y retrato.

[27]

\author{
Cap. XXI, p. 470 \\ Por último menciona a Jerónimo de Villaizan, de la cual destaca su obra A gran \\ mal gran remedio. \\ [A gran] daño [gran remedio.]
}

\title{
ADICIONES Y NOTAS
}

[28]

$$
\text { Cap. IV, nota } 17, \text { p. } 77 \text { (p. 506) }
$$

Los traductores remiten al famoso Buscapié de Cervantes escrito por Adolfo de Castro para ilustrar datos acerca de Diego Hurtado de Mendoza.

¡El Buscapié de Cervantes! ¡Qué vergüenza!... ¿Si los que tal escriben habrán dejado a medio hacer esta traducción por no dar publicidad a la demostración evidente que hace Ticknor, al fin de la obra, de la criminal superchería de D. Adolfo de Castro?...

La. B.

Si los traductores hubiesen tenido presente la edición del Diálogo de la verdadera honra militar hecha en Zaragoza en el año de 1642, hubieran visto en el «Elogio» bio-bio-bibliográfico de Urrea que la precede, escrito por el célebre D. Juan Francisco Andrés de Ustarroz, la noticia expresa de ese libro. Titúlase en efecto Don Clarisel de las Flores: constaba de tres tomos de crecido volumen en folio, y era su poseedor en aquella fecha el Dr. D. Francisco Jiménez de Urrea, Cronista del Reino de Aragón. Además de esta obra dejó m[anuscritas] según el referido «Elogio», las siguientes: 
Una partida de erudición con Gallardo al fondo: las notas inéditas de Cayetano Alberto de la Barrera a la Historia de la literatura española de G. Ticknor

- La Arcadia de Jacobo Sannazaro; traducida en castellano en el mismo género de versos que la escribió su autor. Estuvo próxima a ser impresa: la aprobó D. Alonso de Ercilla. Guardábase en la Librería del Convento de Agustinos de Épila, titulado de San Sebastián.

- El Victorioso Carlos $\left(=5^{\circ}\right)$ : Poema en verso suelto. Existía original en la misma librería.

- La famosa Épila: imitación de la Arcadia de Sannazaro. Poseía este $\mathrm{m}$ [anuscrito] el expresado D. Francisco Jiménez de Urrea.

L. B.

[30]

Cap. VIII, nota 18, p. 166 (p. 547)

\begin{abstract}
Los traductores hacen relación en esta nota de un gran número de obras teatrales representadas en colegios de jesuitas o en conventos de frailes que ocupan un período singular en la historia del drama español anterior a Lope y que no había sido suficientemente estudiado hasta el momento. De los fondos de la Compañía depositados en la Real Academia de la Historia toman la referencia entre otras muchas de la obra titulada Coloquio del primer estudiante y mayorazgo trocado, entre el P. Salas (¿José Antonio González?) y el beato Luis Gonzaga de la compañía de Jesús.
\end{abstract}

¿Aluden aquí los traductores a D. José o Jusepe Antonio González de Salas, el colector de las Poesías de Quevedo? Dicho señor no fue ni soñó en ser jesuita. Éste y el siguiente Coloquio pudieran acaso atribuirse al Padre Pedro de Salas, poeta, autor de Afectos divinos con Emblemas sagrados. ${ }^{19}$

La B.

\title{
TOMO III
}

[31] Cap. XXV, nota 1, p. 80

Sobre la escueta síntesis de noticias bio-bibliográficas que el hispanista ofrece sobre Agustín Moreto siguiendo a Eugenio de Ochoa.

Algo más se sabía de Moreto cuando Ticknor escribió esto con su inexactitud y ligereza acostumbradas. Ahora ya tenemos una excelente

\footnotetext{
${ }^{19} \mathrm{El}$ siguiente coloquio al que se alude La Barrera es el Coloquio de la escolástica triunfante y la nueva Babilonia, por el P. Salas (p. 548). Ambas piezas quedan relacionadas en su Catálogo bajo la entrada «Padre Salas», sin atreverse a unificar con un anterior «Padre Pedro de Salas», autor de El Dómine Lucas y la fiesta en el aire (1618).
} 
bio-bibliografía de este insigne dramático, gracias a la diligencia de los Sres. Luis y D. Aureliano Fernández Guerra, D. Joaquín M. de Alba y algunos otros que han contribuido a ilustrar su colección de Comedias escogidas, ordenada por el primero, tomo XXXIX de la Biblioteca de autores Españoles. ${ }^{20}$

El escueto semblante que Ticknor realiza de Francisco de Bances Cándamo concluye con la pérdida de favor cortesano, las penurias económicas y una muerte en destierro.

No hay tal destierro. Hallándose Cándamo desempeñando la superintendencia de Rentas de San Clemente, fue comisionado por el Consejo para una grave pesquisa en la villa de Lezuzas, donde falleció a poco, envenenado, según sospechas vehementes. Ticknor llama trabajo pobre al del biógrafo de Cándamo, pero su epílogo es el pobre, a mar de inexacto y gratuito. Es también equivocado en gran parte lo que dice sobre la edición de las Obras líricas del mismo autor: sus licencias y censuras son de octubre de 1720: la Dedicatoria y Fe de Erratas de diciembre del mismo año. Cándamo gozó de gran favor con el Rey Carlos II: esto le granjeó poderosos émulos. Ciertas alusiones satíricas de su comedia El esclavo en grillos de oro hubieron de costarle caras, le salvó su valor; y al fin creyó conveniente dejar la Corte, pasando a servir en diferentes provincias empleos de consideración. ${ }^{21}$

Denuncia Ticknor las escasas noticias acerca de ciertos poetas de mérito incluidos en las Flores de poetas ilustres de Pedro Espinosa (1605), hasta el punto de considerarlos desconocidos u «oscuros». Salvedad hecha de las breves indicaciones proporcionadas por Nicolás Antonio, nada puede añadir sobre Cristobalina Fernández de Alarcón, Hipólita y Luciana de Narváez, Pedro Liñán o Agustín de Tejada, al que reconoce únicamente los poemas editados en las Flores.

\footnotetext{
${ }^{20}$ La obra se imprimió en Madrid, M. Rivadeneyra, 1856.

${ }^{21}$ Cf. el extenso artículo dedicado a Francisco Antonio de Bances Cándamo en el Catálogo (pp. 6468), donde la biografía del autor resulta enriquecida respecto a la ya existente. Ticknor califica en efecto de «trabajo muy pobre» el relato de su vida que va al frente de la edición de las Poesías líricas (Madrid, s. a., pero con fe de erratas de 1710, licencias de 1720 y dedicatoria de 1729).
} 
Una partida de erudición con Gallardo al fondo: las notas inéditas de Cayetano Alberto de la Barrera a la Historia de la literatura española de G. Ticknor

Casi todo cuanto aquí se dice es inexacto o mezquino. Acerca de $\mathrm{D}^{\mathrm{a}}$ Cristobalina ya añaden algo los traductores. Del Dr. Tejada Páez hay muchas más composiciones. Pedro Liñán de Riaza, eminente ingenio aragonés, amigo íntimo de Lope, no es oscuro ni desconocido para ninguno de los que manejan con atento estudio nuestros antiguos libros de bella literatura. ${ }^{22}$

22 El Cancionero de poetas varios españoles de los siglos XVI y XVII (1852-1862) que dejó manuscrito C. A. de la Barrera demuestra a las claras la falta de diligencia de Ticknor en este tratamiento de autores menores. El sistemático y riguroso repaso de nuestro erudito por poemas y textos panegíricos así como por artes retóricas de este tiempo descubre la fama de la que estos poetas gozaron. Meros asomos a La Arcadia, La Filomena, El laurel de Apolo o La Dorotea de Lope hubieran acuñado un perfil suficiente para Pedro Liñán; la consulta de la Biblioteca Hispana Nova de N. Antonio o el Viaje del Parnaso de Cervantes hubiera evitado que figuras como las de Cristobalina Fernández de Alarcón o Agustín de Tejada se presentasen desdibujadas en esta primera historia nacional de la literatura española. Precisamente con ellos y algunos otros poetas de menor estima, La Barrera pensó completar su Cancionero:

He reunido en este primer tomo, seccionado en dos volúmenes, los artículos que tenía concluidos y dispuestos para una extensa colección que proyectaba formar bajo el mismo título de Cancionero de Poetas varios. En ella debían de incluirse las obras poéticas de algunos de nuestros ingenios menos conocidos; ilustradas convenientemente con puntuales noticias de sus autores. Aquí pensaba compilar, además de las que comprenden ya estos volúmenes, las de Pedro Liñán de Riaza, Miguel Cid, el Conde de Salinas, Baltasar Elisio de Medinilla, Miguel Cejudo, Fernando de Soria Galvarro, Da Cristobalina Fernández de Alarcón, Agustín de Tejada Páez, D. Francisco de la Cueva y Silva, y otros diferentes: conciliando la circunstancia de ser el poeta, cuando no ignorado, escasamente conocido, mereciendo estima sus obras métricas; y la de no exceder éstas de los límites al que debe reducirse una colección de esta especie.

Esta laguna de Ticknor, que tal vez sirvió de estímulo al proyecto de La Barrera, supuso con certeza retórico acicate al trabajo de F. Rodríguez Marín Pedro Espinosa. Estudio biográfico, bibliográfico y crítico (Tip. de la Revista de Archivos, Madrid, 1907, pp. 7-8). Apoyado en los materiales acumulados por el antequerano J. Quirós de los Ríos, el Bachiller de Osuna reivindicó en torno al colector de las Flores la vida y la obra de los ingenios participantes en la antología y denunció las cortas miras del hispanista. Vertió en esta obra todo el material que serviría de base a una extensa biografía sobre la poetisa Fernández de Alarcón que no llegó a realizarse y que aumentaba considerablemente los escasos datos aportados en las «Adiciones y notas» (p. 507) por los traductores del libro de Ticknor. Distinta fortuna corrió el poeta Agustín de Tejada, cuya biografía aún no ha sido esbozada más allá de lo retratado por Rodríguez Marín y cuya obra aún no ha sido reunida en conjunto (cf. B. Molina, «Agustín de Tejada y las Flores de poetas ilustres de Pedro Espinosa», Analecta Malacitana, XXIV, 2, 2001, pp. 353-402). 
Belén Molina Huete

[34]

Cap. XXIX, p. 197

En la nómina de autores relevantes ausentes en la antología de Espinosa, destaca Ticknor tras el nombre de Fernando de Herrera el del valenciano Andrés Rey de Artieda.

De Artieda se halla en las Flores una composición bajo el seudónimo anagramático de Misser Tiedra. ${ }^{23}$

[35]

Cap. XXIX, nota 48, p. 212

Entre los seguidores de la poesía de Góngora enumera Ticknor a Francisco de la Torre, murciano, poeta de «mal gusto», a quien hace autor de Entretenimiento de las musas en esta nueva baraja de versos, dividida en cuatro manjares... por Fénix de la Torre (Zaragoza, 1654).

Tres veces habla Ticknor de D. Francisco de la Torre y Sevil sin saber que trata de un mismo autor. Aquí, despreciándole injustamente y haciéndole murciano; en la página 232 dándole por desconocido y no menos despreciable; en la 250 alabándole como traductor de Owen y su continuador. Esta última vez le supone aragonés. Fue catalán: de Tortosa. Con mayor injusticia todavía juzga aquí al ingeniosísimo y malogrado discípulo de Calderón, D. Agustín de Salazar y Torres. ${ }^{24}$

Al margen de los designios culteranos sitúa Ticknor al poeta Francisco de Medrano, «a quien ningún trabajo parece haber costado el libertarse del contagio de su tiempo».

\footnotetext{
23 Se trata del soneto «Vive casi en la bienaventuranza», que con algunas variantes y titulado Contra la esperanza fue editado por el propio autor el mismo año en los Discursos, epístolas y epigramas de Artemidoro, Angelo Tanvano, Zaragoza, 1605.

${ }^{24}$ En la p. 232 Ticknor considera a Francisco de la Torre y Sevil como autor desconocido integrado en la antología de 1680 titulada Varias hermosas flores del Parnaso, a la cual califica por extensión de decadente al compararla con la de Espinosa. En la p. 250 lo hace buen autor de poemas cortos de índole epigramática con carácter festivo. La Barrera interpreta que lo hace aragonés al afirmar Ticknor que «parece sacudir sus cadenas e influencia al recordar que era paisano de Marcial». En esta misma página, el hispanista alaba su traducción de los epigramas latinos del protestante inglés Juan Owen (muerto en 1622) que despojó de susceptibles censuras y que aumentó con epigramas originales. De Agustín de Salazar, Ticknor critica su Cítara de Apolo que se editó en 1677, «producción tan mala o peor que las de sus antecesores del mismo género, y por lo tanto digna de cerrar esta lista». A Francisco de la Torre y Sevil dedica La Barrera un largo artículo en su Catálogo con noticias inéditas sobre el autor facilitadas por A. Fernández Guerra (pp. 399-402).
} 
Una partida de erudición con Gallardo al fondo: las notas inéditas de Cayetano Alberto de la Barrera a la Historia de la literatura española de G. Ticknor

$\mathrm{Ni}$ Medrano, ingenio tan insigne cuanto desconocido de nuestros modernos críticos, ni Herrera, ni mucho menos Rioja en sus afectados sonetos, ni en fin el mismo Garcilaso estuvieron exentos del culteranismo, que, nacido en la época de Juan de Mena, comenzó latinizando la construcción, alambicando los conceptos y adornado pomposamente el estilo, y han concluido en la presente con las sutilezas ideológicas de Zorrilla y sus adeptos.

La apostilla al pie de Ticknor recuerda que nada se conoce de la obra de Medrano salvo su reimpresión conjunta en 1617 con una traducción ovidiana a cargo de Pedro Venegas de Saavedra. Aunque este último autor era natural de Sevilla, siguiendo a Nicolás Antonio se afirma que la edición fue realizada en Palermo.

Lo que sospecha Antonio es todo lo contrario, pero sin fundamento: la edición es de Palermo, y hecha por un editor-impresor ilustradísimo. ${ }^{25}$

En la enumeración de sonetos debidos a Juan de Arguijo, Ticknor da el número de 29.

Ticknor no ha conocido la preciosa colección de Sonetos hallada y publicada por D. J. Colón y Colón en Sevilla (1841) debidos a la pluma de Arguijo y anotados por el Maestro Francisco de Medina. Con estos ascienden a 61 los de aquel grande ingenio (no incluyendo los laudatorios) que son de lo mejor que en este género atesora nuestro Parnaso.

Si hubiéramos de añadir aquí mención de los poetas líricos dignos de ella y pertenecientes a esta época célebre, que Ticknor omite, no tendríamos espacio suficiente. Muchos añaden los traductores,

\footnotetext{
${ }^{25}$ Los datos de la edición palermitana de la obra de Medrano encabeza las «Noticias» acerca de este poeta recogidas en el citado Cancionero de La Barrera (p. 45): «En el año de 1617 vio la luz pública en la ciudad de Palermo, por diligencia del ilustrado impresor italiano Ángel Orlandi, un precioso librito de Poesías Castellanas, comprensivo de las que aparecen de su título, que es el siguiente: Remedios de Amor de Don Pedro Venegas de Saavedra. Con otras diversas Rimas de Don Francisco de Medrano. Al Ilmo. y Excmo. Sr. Duque de Feria, Virrey y Capitán General del Reino de Valencia. (Esc[udo]). En Palermo, por Angelo Orlandi y Decio Cirilo. Año 1617. (8)». Sigue la reproducción de los preliminares de dicha edición y el índice de poemas que comprende.
} 
Belén Molina Huete

olvidando entre otros al ilustre ingenio de Nájera, Fr. Juan de Salinas y Castro, digno conterráneo del autor de Las Eróticas. ${ }^{26}$

En el breve espacio que Ticknor otorga a Francisco de Rioja, reduce la biografía a su carácter de eclesiástico sevillano (1600-1658) con puesto en la Inquisición y afecto al Conde-duque de Olivares. Sus últimos días sucedieron en Sevilla plácidamente donde se entregó al ejercicio de las Letras.

Esta pretendida noticia de Rioja contiene pocos menos errores que palabras. Al imprimirse el presente tomo, concluía yo de redactar la primera biografía de tan ilustre ingenio escrita con aproximada exactitud y rica de preciosos datos, para colocarla al frente de la edición que preparo de sus Poesías hecha por sus genuinos originales existentes en la Biblioteca Nacional.27

L. B.

\begin{abstract}
Cap. XXXVI, nota 35, p. 346
La novela corta del XVII deviene con diferentes propuestas que dan variedad al género. En este sentido, a mediados del siglo, se constatan dos corrientes hasta cierto punto innovadoras aunque poco significativas. La primera de ellas añadiendo un carácter religioso, y se representaron las Soledades de Aurelia de Jerónimo Fernández de la Mata (1637) que imitó Cristóbal Lozano en su exitosa Soledades de la vida. En las noticias dadas en nota, Ticknor alude a que el Índice expurgatorio de 1790 atribuye la obra a un Gaspar Lozano, al parecer distinto del verdadero autor.
\end{abstract}

${ }^{26}$ El cálculo de sonetos de Juan de Arguijo responde sin duda a la valoración por parte de La Barrera de los poemas en este metro seleccionados por M. J. Quintana para el tomo XVIII de la Colección de "Ramón Fernández» (Poesías inéditas de Francisco de Rioja y otros poetas andaluces, 1797) y de la citada edición a cargo de J. Colón y Colón, la cual reprodujo parcialmente las correcciones del maestro Medina. Haciendo acopio de los sonetos descubiertos con posterioridad, la moderna edición de la Obra completa de Juan de Arguijo debida a S. B. Vranich (Albatros, Valencia, 1985) ofrece un cómputo definitivo de 66 sonetos, más uno laudatorio. Por primera vez de forma íntegra han visto la luz las anotaciones de Francisco de Medina en la Poesía del poeta sevillano preparada por G. Garrote y V. Cristóbal (Colección «Clásicos Andaluces» de la Fundación José Manuel Lara, Sevilla, 2004).

${ }^{27}$ La edición de las Poesías de Francisco de Rioja vio efectivamente la luz en 1867. Años más tarde, en 1872, la Sociedad de Bibliófilos Andaluces de Sevilla publicaba unas Adiciones también debidas a nuestro erudito. 
Una partida de erudición con Gallardo al fondo: las notas inéditas de Cayetano Alberto de la Barrera a la Historia de la literatura española de G. Ticknor

Las Soledades de la vida, con 4 Comedias del autor, que ya fueron suprimidas en su $2^{\circ}$ edición, se publicaron bajo el nombre de D. Gaspar Lozano Montesino, sobrino del ingenioso Dr. Cristóbal Lozano, que no quiso declararse novelista, ni autor de comedia tan profana como $E l$ estudiante de día y galán de noche. No debe ser confundido el dicho D. Gaspar con el canónigo de León Gaspar Lozano y Regalado, que escribió la curiosa obra poética titulada Loores de los Santos, impresa en Valladolid, 1619.

Enumerando las raras obras que dentro del género de novela corta jugaron con la omisión de una vocal a lo largo de su texto, imitación de los Varios efetos de amor de Alonso de Alcalá (1641), señala Ticknor la titulada Méritos disponen premios (1654) que da como de Fernando Jacinto de Zárate.

No es Zárate sino Zurita: D. Fernando Jacinto de Zurita y Haro, Señor de El Villar del Saz y Veinticuatro perpetuo de Jerez de la Frontera.

En los datos bibliográficos de la conflictiva obra debida al Padre Mariana Discurso de las enfermedades de la compañía de Jesús (1625), Ticknor da noticia de cómo desde su publicación en el Índice expurgatorio de 1667 se creyó durante siglo y medio manuscrito de desconocido autor. Hasta que en 1768, al poder reimprimirse tras la expulsión de la Compañia, una «disertación formal» probó que el P. Mariana fue su autor.

Esta disertación, apreciable trabajo crítico-bibliográfico, se imprimió anónima al frente del Discurso, y fue obra del Académico D. José Miguel de Flores y La Barrera, mi tío, magistrado insigne a cuyas tareas y apasionado gusto debieron mucho las letras en la gloriosa época de Carlos III y ya en la de su antecesor. El Sr. Pi y Margall colector de la moderna edición de Mariana (Biblioteca de Autores Españoles, t. ) no se ha dignado de reimprimirla ni de citar a su autor.

L. B. 
Ticknor da como fecha de impresión sevillana de La Filosofía vulgar de Juan de Mal Lara el año de 1558.

$1568^{28}$

[44]

Cap. XXXIX, nota 43, p. 413

Tras enumerar los distintos años en que se publicó el Jardín de flores curiosas de Antonio de Torquemada (1570, 1575, 1587, 1589), Ticknor enuncia: «La primera edición de Amberes, 1575, 12º, ocupa 536 páginas». [La Barrera tacha la palabra «primera»].

La primera edición es de Salamanca, 1570. Poseo una de Medina del Campo, $1599,8^{\circ}$.

\section{NOTAS Y ADICIONES}

Gayangos y Vedia, siguiendo la autoridad del Índice expurgatorio de 1790, reúnen en un mismo autor a Fernando de Zárate y a Antonio Enríquez Gómez.

El débil fundamento de esa conjetura se halla ya desvanecido. Los redactores del Índice no tuvieron otro que el haber visto impresa bajo el nombre de Zárate una comedia de Enríquez. Razones críticas incontestables, apoyadas en datos cronológicos, demuestran la imposibilidad de que Enríquez Gómez escribiera la mayor parte de los dramas que corren con el nombre de Zárate. Por último, la existencia real de este autor (D. Fernando de Zárate y Crastronovo) se encuentra comprobada de un modo que deja poco lugar a la duda. Véase mi Catálogo biogr[áfico] del Teatro antiguo español. ${ }^{29}$

${ }^{28}$ En el original, 1558 (III, p. 159).

${ }^{29}$ Cf. las pp. 134-142 para Enríquez Gómez y pp. 506-508 para Zárate. Hay error en La Barrera. Hoy se acepta la hipótesis de Adolfo de Castro en relación a la identidad de ambos autores con el nombre de Antonio Enríquez Gómez siguiendo el argumento expuesto por Gayangos y Vedia. Documentos de la Inquisición sevillana especifican, tras la muerte de Antonio Enríquez Gómez (ocurrida en esa ciudad el 19 de marzo de 1663), que tuvo como «alias Don Fernando de Zárate». Véase la más reciente aportación documental al respecto, el libro de H. Cordente, Origen y genealogía de Antonio Enríquez Gómez, alias Don Fernando de Zárate, Cuenca, Alcana Libros, 1992, pp. 16-18. 
Una partida de erudición con Gallardo al fondo: las notas inéditas de Cayetano Alberto de la Barrera a la Historia de la literatura española de G. Ticknor

L. B.

Entre los poemas históricos narrativos de la segunda mitad del XVII, Ticknor encabeza la lista de los menos relevantes con la Historia Parthenopea de Alfonso Fernández. En la nota correspondiente, el propio Ticknor da la fecha de 1511 como impresión de la obra, aunque sin reparar en el anacronismo. Son los traductores quienes remarcan en sus adiciones que el poema no pertenece a este período, sin privarse sin embargo de hacer una extensa descripción de la pieza. Al final de ésta, La Barrera hace una llamada.

A este lugar correspondía también la cita del poema titulado La celestial jerarchia y inffernal labirintho de que hablo en mi nota marginal a la pág. 442 del tomo $1^{\circ}$. Al catálogo de poemas que de esta obra de Ticknor y de sus ricas «Adiciones» resulta pueden agregarse aún algunos otros, impresos y manuscritos. Véase por de pronto el tomo XXIX de la Biblioteca de Autores Españoles. ${ }^{30}$

Precisa esta nota de los traductores la información bibliográfica que Ticknor había ofrecido en su texto acerca del poema religioso de tintes épico-narrativos titulado La universal redención, obra de Francisco Hernández Blasco. En este sentido, a las ediciones indicadas por el hispanista, añaden las de Toledo de 1589 y 1598 y la última de Alcalá en 1612 a cargo de Juan Gracián, sobre la que sitúa la llamada La Barrera.

Poseo la edición de Madrid, por Luis Sánchez, 1612, en $4^{\circ}$, con grabados y que no conocen Ticknor ni sus traductores. Salvá cita en su Catálogo gr[ande] otra de Alcalá, 1621, $4^{\circ}$.

Los poemas narrativos de tema legendario encuentran un buen ejemplo para Ticknor en Los amantes de Teruel de Juan Yagüe de Salas (1616). A pesar del credo histórico que el autor hubo de dar a su versión aportando documentos fehacientes (1619), su ficción vino a resolverse en 1806 aunque ya la tradición había arraigado profundamente en España. Los traductores se ven en la obligación de remontar la relación de la historia al canto IX del Florando de

30 Se refiere don Cayetano al segundo volumen de los Poemas épicos dispuesto y anotado por C. Rosell en 1854 y reimpreso en 1866. 


\begin{abstract}
Castilla de Jerónimo Huerta, de 1588; y a recalar en otros intentos anteriores al de Yagüe, como el del drama de Rey de Artieda de 1599 o la curiosa y rara versión en verso de Pedro de Alventosa (s. l., s. a.) que los anotadores suponen anterior a 1555 o la manuscrita debida a Bartolomé de Villalba y Estaña en 1577.31
\end{abstract}

Es muy apreciable para la ilustración crítica e histórica de esta célebre tradición, algo desfigurada, pero sin duda positiva, el opúsculo titulado Historia de los Amantes de Teruel, escrito por D. Esteban Gabarda y publicado en Valencia, 1842, $8^{\circ}$. El Sr. Gabarda, a pesar de no conocer las obras citadas en esta «Nota» o «Adición» de los traductores, refuta con victoriosas razones y estimables documentos al geógrafo Antillón que por cierto no se mostró muy erudito en este punto.

Ampliando el perfil de Pedro Soto de Rojas, del que poco aporta Ticknor, los traductores hacen mención de una introducción en prosa de Francisco de Trillo y Figueroa al poema del granadino El Paraíso. Sin haber sido aludido por Ticknor en el texto correspondiente a la adición, Gayangos y Vedia se permiten un breve apunte sobre el poeta al haber sido citado con anterioridad. Califican su poesía de «escaso mérito».

Calificación injusta en alto grado. Trillo y Figueroa, imitador felicísimo de Góngora en sus poesías del género festivo y picaño, merece bien el lugar que le ha dado el Sr. Castro en la colección de líricos hecha para la Biblioteca de Autores Españoles. Poco ha debido el agudo Trillo (coruñés) a su paisano el Sr. Vedia. A pesar de su erudita diligencia, los traductores olvidan aún a muchos peregrinos versistas de esta época.

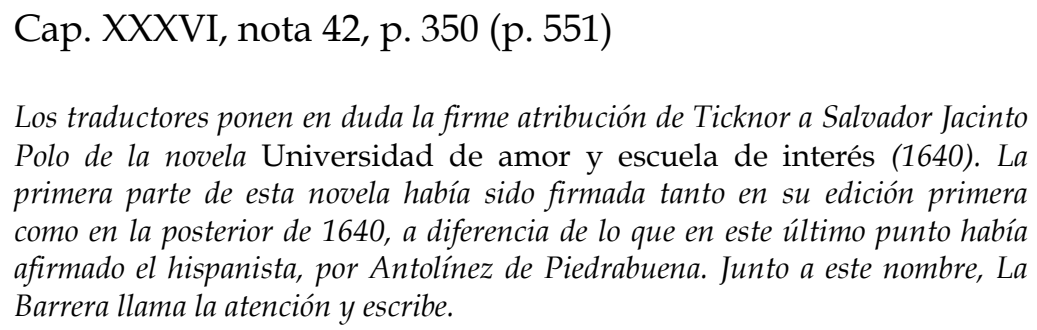

Los traductores ponen en duda la firme atribución de Ticknor a Salvador Jacinto Polo de la novela Universidad de amor y escuela de interés (1640). La primera parte de esta novela había sido firmada tanto en su edición primera como en la posterior de 1640, a diferencia de lo que en este último punto había afirmado el hispanista, por Antolinez de Piedrabuena. Junto a este nombre, La Barrera llama la atención y escribe.

Anagrama de Jacinto Polo de Medina.

\footnotetext{
${ }^{31}$ Curiosamente los traductores hacen autor del drama a «Francisco Rey de Artieda, aragonés» sin que nada advierta La Barrera sobre el cambio del verdadero nombre: Andrés.
} 
Una partida de erudición con Gallardo al fondo: las notas inéditas de Cayetano Alberto de la Barrera a la Historia de la literatura española de G. Ticknor

En una breve expansión biográfica del Dr. Domingo Becerra, traductor en 1585 del Galateo de Giovanni della Casa que Ticknor había traído a colación por el libro del mismo nombre de Gracián Dantisco (1599), los traductores apuntan a su prisión en Argel, aludida en la dedicatoria de la obra.

Fue presbítero; estuvo en Argel cautivo al mismo tiempo que Cervantes y fue rescatado con él, año de 1580; tenía entonces 45 de edad. Sirvió en su cautiverio al Rey Azán; y el infame Blanco de Paz le imputó la delación que él mismo había hecho del proyecto de fuga. No declaró en la Información de Cervantes; éste le celebró con encarecimiento en su Galatea (Canto de Caliope).

\title{
TOMO IV
}

\begin{abstract}
Los comienzos del XVIII traen consigo una poesía decadente. Entre las primeras manifestaciones de lírica narrativa, Ticknor alude, y no precisamente por su valía, a dos poemas burlescos: La Proserpina, de Pedro Silvestre (Madrid, 1721) y La Burromaquia, fragmento que ha localizado entre las Obras póstumas de Gabriel Álvarez de Toledo. Sigue asimismo la referencia a ciertos extractos de un poema del P. Butrino dedicados a Santa Teresa (1722) y de otro poema a San Jerónimo escrito por Francisco de Lara (1726).
\end{abstract}

A estas noticias, que los traductores amplían en su nota de la pág. 398, agréguese la del poema titulado San Rafael, custodio de Córdoba, escrito por Fr. Buenaventura Terrin, trinitario, y dado a la estampa en Madrid, $1736,4^{\circ}$. Lleva a su principio composiciones panegíricas de Gerardo Lobo y de Cañizares. ${ }^{32}$

\footnotetext{
32 Gayangos y Vedia dan los datos exactos de los poemas correspondientes al P. Josef Butron y a Francisco de Lara de los que Ticknor sólo había conocido un extracto: Harmónica vida de Santa Teresa de Jesús, fundadora de la reforma de Carmelitas Descalzos y Descalzas (Madrid, Francisco del Hierro, 1722, 4º); El Sol Máximo de la Iglesia, San Jerónimo, Poema heroico en octavas ritmas (Sevilla, Francisco Sánchez Reciente, 1726, 4º).
} 
Junto con las de otros autores próximos, al tratar de José Joaquín Benegasi y Luján como uno de los pocos poetas reseñables del reinado de Felipe $V$, da Ticknor en nota la cita bibliográfica completa de sus Poesías líricas y jocoserias, Madrid, $1743,4^{\circ}$.

Su padre D. Francisco, caballero de Calatrava, Consejero de Hacienda Pública, escribió poesías del mismo género y algunos entremeses y bailes. Publicó varios de éstos D. José en Madrid, 1744; y las obras líricas con otros entremeses, año 1746. En uno y otro libro incluyó obras suyas. ${ }^{33}$

Destaca Ticknor la tarea de J. J. López de Sedano como restaurador de la poesía antigua española en su Parnaso (1768-1778). En nota se hace eco de su crítica acogida y de la respuesta que bajo seudónimo hizo el autor en diversos cuadernos.

Se atribuye también a Sedano el papel periódico titulado el Belianís literario.

\begin{abstract}
El proceso de compilación póstuma de la obra de Fr. Diego González es narrada por Ticknor como ardua labor de su amigo Juan Fernández, ya que el poeta no dio importancia a su poesía y no se preocupó de su conservación. En nota, se añade la ficha bibliográfica de las Poesías de Fr. Diego, de las que se da como fecha 1812. El comentario siguiente cierra la nota: «Si hubiera tenido menos modestia, y no tanta intimidad con Jovellanos y Meléndez, tal vez tuviéramos hoy una escuela moderna de Sevilla, como tenemos la de Salamanca».
\end{abstract}

Traslado a los discípulos y eternos encomiastas de la escuela políticoliteraria de los Listas y Reinosos. Las Poesías de González se publicaron en 1796. No hubo tal dificultad en reunirlas: su editor, infiel al mandato del autor, moribundo, las salvó de la hoguera en que a su vista hizo quemar éste varios papeles.

33 Sobre D. Francisco Benegasi y Luján y su hijo José Joaquín trata La Barrera en su Catálogo (pp. 35-37) con detallado índice de las obras y comentarios biográficos. 
Una partida de erudición con Gallardo al fondo: las notas inéditas de Cayetano Alberto de la Barrera a la Historia de la literatura española de G. Ticknor

Como "primera comedia ajustada a las reglas francesas que apareció en castellano» remite Ticknor a La razón contra la moda, de Luzán (1751), de la que en nota da cuenta de su publicación sin nombre de autor y con un breve discurso en forma de dedicatoria en defensa de las reglas clásicas.

Firma Luzán la dedicatoria con el seudónimo de El Peregrino, que llevaba en la referida Academia del Buen Gusto.

\section{APÉNDICE A}

\section{Del origen de la lengua castellana}

[57] p. 190

Acerca de la "proporción exacta» con que cada una de las lenguas influyentes contribuyó en la formación del castellano, Ticknor recuerda que "G...» aumenta la participación del árabe en un octavo. La Barrera desarrolla la abreviatura.

\section{Gayangos.}

[58] nota 62, p. 191

Cerrando una breve bibliografía en nota sobre esas lenguas que dieron origen a la lengua española, Ticknor reseña «un artículo del British and foreign Review (número XV, 1839), escrito por D. P. de G.».

\section{Pascual de Gayangos.}

\section{APÉNDICE B}

\section{De los romanceros}

[59] p. 201

Descripción de la secuencia editorial de la recuperación del romancero antiguo español que se detiene profusamente en el elogio a las empresas de Agustín Durán. 
Nada deja que desear el Romancero del Sr. Durán en punto a riqueza, ilustración y método. No así por lo respectivo a la genuina reproducción del texto. El colector, llevado de su ingenio y gusto, se ha permitido restaurar, suplir y corregir libremente las faltas y errores de las viciadas impresiones antiguas, licencia a que han aludido implícitamente Wolf y Hofmann en su Primavera y Flor de Romances; y que le fue agriamente criticada por el erudito D. Luis de Usoz y Río, ya en un artículo que insertó el periódico titulado El clamor público (3 de abril de 1851), ya de palabra en una acalorada disputa que sostuvieron en el Ateneo. Otro artículo suelto publicó el mismo Usoz (Clamor del 31 mayo, id.), impugnando el elogio que del mismo Romancero hicieron en esta traducción los Sres. Gayangos y Vedia.

\section{APÉNDICE D Sobre el Buscapié}

$[60]$ p. 207

Ante la calificación de «no muy importante» para este librito atribuido a Cervantes por «algunos».

Esta cuestión es de las más importantes que puede ofrecer nuestra Historia literaria. Véase acerca del origen de la tal patraña del Buscapié, mi artículo inserto en la Revista de Ciencias, Literatura y Artes de Sevilla, tom. $2^{\circ}$ y $3^{\circ}$. Escrito por un quidam oscuro ¿qué mucho que no le citen los traductores? 34

\footnotetext{
34 Se refiere La Barrera a sus «Conjeturas sobre el fundamento que pudo tener la idea que dio origen a la patraña del Buscapié» (1856-1859). La obra más sólida en este sentido fue finalmente El cachetero del «Buscapié». Resumen de las pruebas y razones críticas que evidencian la falsedad del «Buscapié» de Don Adolfo de Castro y la del otro tal que se mintió en el pasado siglo (1849-1866) dada a luz por F. Rodríguez Marín en 1916. En este asunto concreto La Barrera seguía de cerca a B. J. Gallardo, a quien también debemos ilustre bibliografía en contra de esta superchería literaria (cf. A. Rodríguez Moñino, op. cit., pp. 228-236 y A. Pérez Vidal, op. cit., pp. 393- 400). Para la completa labor de don Cayetano a este respecto, y en general sobre Cervantes, pueden verse las abundantes y salpicadas citas en L. Rius de Llosellas, Bibliografía crítica de las Obras de Miguel de Cervantes Saavedra, Lib. de M. Murillo, Madrid, 1895-1905, 3 vols.
} 
Una partida de erudición con Gallardo al fondo: las notas inéditas de Cayetano Alberto de la Barrera a la Historia de la literatura española de G. Ticknor

[61] p. 231

\begin{abstract}
A la irreverencia explícita de Adolfo de Castro ante un extranjero que venga a opinar sobre la autenticidad de cualquier obra española, Ticknor responde que tampoco sería válido, pues, para elaborar historias literarias «porque las cuestiones sobre la autenticidad de Cibdareal, de Tomé de Burguillos, del bachiller La-Torre y del Gil Blas, todas han de discutirse y resolverse en obras de esta naturaleza».
\end{abstract}

Ticknor estima por ficticias las poesías del Br. Francisco de la Torre. ¿Por qué los traductores no anotan ahora este pasaje, o el de la pág. 207, haciendo mención y debido resumen del excelente trabajo sobre este punto recientemente publicado por D. Aureliano Fernández Guerra? (Discurso leído en la Academia Española, 1857). Demuéstrase en él la autenticidad cronológica de esas poesías, escritas a mediados del siglo XVI, y se prueba con preciosos datos la existencia real de Francisco de la Torre, nacido en Torrelaguna, año de 1533.

[62] p. 232

Concluye Ticknor este apéndice justificando su incursión en el tema cervantino del Buscapié como serio examen más allá de su nacionalidad y movido por su amor a la literatura española.

¡Víctor mil veces por esta réplica vigorosa y contundente! Bien coincidimos en herir y anonadar al moderno Lupián. ${ }^{35}$

L. B.

\title{
NOTAS Y ADICIONES DE LOS TRADUCTORES
}

[63]

Cap. II, p. 26 (pp. 398-399)

Dan cuenta los traductores del auge de la poesía popular durante la guerra de Sucesión, nombrando algunos de los temas más recurrentes y algunos de los títulos más significativos.

\footnotetext{
35 Se refiere a Adolfo de Castro, que como Lupián Zapata escribió unas mordaces cartas a B. J. Gallardo (cf. A. Rodríguez Moñino, op. cit., pp. 234-235).
} 
Escribiéronse y vieron la luz durante, o poco después de la guerra de Sucesión algunas otras producciones poéticas dignas de cita, aunque generalmente de pésimo gusto. De ellas tengo el Santo Thomás de Villanueva, poema en quintillas, por D. Miguel de Vargas Machuca (Nápoles, 1706); y la Epopeya panegírica de los triunfos del Príncipe Eugenio de Saboya (Nápoles, 1718) por D. Vicente Díaz de Sarralde. No faltaron entre tales escritores algunos partidarios españoles del Archiduque Carlos, como lo fue el expresado Sarralde, que se titula del Consejo de S. M. C. y Alcalde de su Real Casa y Corte.

L. B.

Los traductores proceden a la descripción de los componentes conocidos de la Academia del Buen Gusto madrileña. Entre ellos, aluden al Justo desconfiado, que identifican con el «marqués de Montellano».

El Duque de Montellano. Pertenecían también a esta Academia, la Duquesa viuda de Arcos, el Duque de Béjar y el Conde de Saldaña.

Cap. IV, nota 23, p. 69 (p. 401)

Sobre la producción erudtia del P. Sarmiento, los traductores inciden en su abundancia reconociendo que la mayor parte permanece manuscrita, salvadas un par de obras y algunos opúsculos publicados por «sus aficionados».

Imprimiéronse varios de sus opúsculos en el Seminario erudito de Valladares; y otros en el Correo literario de Europa.

Amplían los traductores la nómina de romanceros ofrecida por Ticknor en el Apéndice B. Y comienzan con la Silva de varios romances. La creencia general de que su edición príncipe fue la de Zaragoza de 1550, y que ésta sirvió de modelo a la publicada en Amberes por Martín Nucio (s. a.) que compartieron en su día ellos mismos, ha de ser corregida siguiendo los sólidos argumentos de F. J. Wolf en el prólogo de su Primavera y flor de romances.

Primavera y Flor de Romances o Colección de los más viejos y más populares romances castellanos, publicada con una introducción y notas por Don Fernando José Wolfy Don Conrado Hofmann, Berlín, En casa de A. Asher y 
Una partida de erudición con Gallardo al fondo: las notas inéditas de Cayetano Alberto de la Barrera a la Historia de la literatura española de G. Ticknor

comp., Imprenta de Gustavo Lange, 1856. Dos tomos, $8^{\circ}$ marg. Colección la más genuina y concienzuda de cuantas han visto de su clase la pública luz: ilustrada con una erudita y profunda disertación y con preciosas noticias bibliográficas.

Apéndice D, p. 207 (p. 409)

Gayangos y Vedia indican que la última parte de este Apéndice Sobre el «Buscapié» corresponde a la serie de artículos publicados por G. Ticknor respondiendo a Adolfo de Castro en el Heraldo, con fecha 10 y 18 de octubre de 1855. La Barrera hace corrección del año, que sí aparece correctamente en la presentación de los textos que en su lugar hace el propio Ticknor.

1850

[68]

Apéndice D, p. 207 (p. 409)

Los traductores se pronuncian definitivamente acerca del Buscapié, al que califican de «juguete literario» $y$ «travesura» de Adolfo de Castro, que al fin ha sido descubierta.

¡Loada sea la verdad! Ya no es El Buscapié «de Cervantes», como lo era en el segundo tomo. ¡Cuánto pudiéramos decir sobre la alta moralidad de esta nota de los traductores, y sobre el respeto debido a la memoria y renombre del gran Cervantes! Quédese para el discreto lector. (¿Qué son creencias históricas?... $)^{36}$

La B.

\footnotetext{
${ }^{36}$ La intención que los traductores ven en Castro es la de retar y divertirse a costa de la crítica, de sus «amigos y cofrades en el estudio de las letras». La nota de La Barrera guarda más ironía si se lee la conclusión literal del comentario a cargo de Gayangos-Vedia: «Hay cierta vanidad literaria en embaucar a los que de críticos se precian y se llaman maestros en estas materias; vanidad que nada tiene de reprensible cuando se trata de un supuesto hallazgo, que, como el presente, nada afecta las creencias históricas y religiosas de nuestro país. A este sentimiento parece haber cedido el Sr. Castro; y si, como hemos oído asegurar, algunos de nuestros literatos creyeron en un principio que el Buscapié era efectivamente obra del inmortal Cervantes, el Sr. Castro debe estar pagado y satisfecho, aunque otros, o más incrédulos o más versados en los misterios de nuestra lengua y literatura, hayan desde luego descubierto su travesura».
} 
Recoge el Apéndice H que preparó Ticknor la edición de algunas poesías inéditas que habian llegado a sus manos y que podian dar «mayor ensanche» a su obra. El número 5 es la titulada aquí Danza general de los muertos. Sobre la frecuencia de este tema no sólo en latín sino en todas las literaturas europeas, los traductores remiten a un artículo del Marqués de Pidal acerca de un "fragmento inédito de poema antiguo castellano».

Este trabajo es un excelente artículo impreso en el Diario Español y reproducido en la Gaceta del $1^{\circ}$ de Julio de 1856, donde el Dr. Pidal (sin dar su nombre) publica y analiza eruditamente cierto fragmento de un poema castellano anterior al siglo $\mathrm{XV}$; fragmento hallado poco antes por D. Tomás Muñoz en el Archivo de la Academia de la Historia. 
Una partida de erudición con Gallardo al fondo: las notas inéditas de Cayetano Alberto de la Barrera a la Historia de la literatura española de G. Ticknor

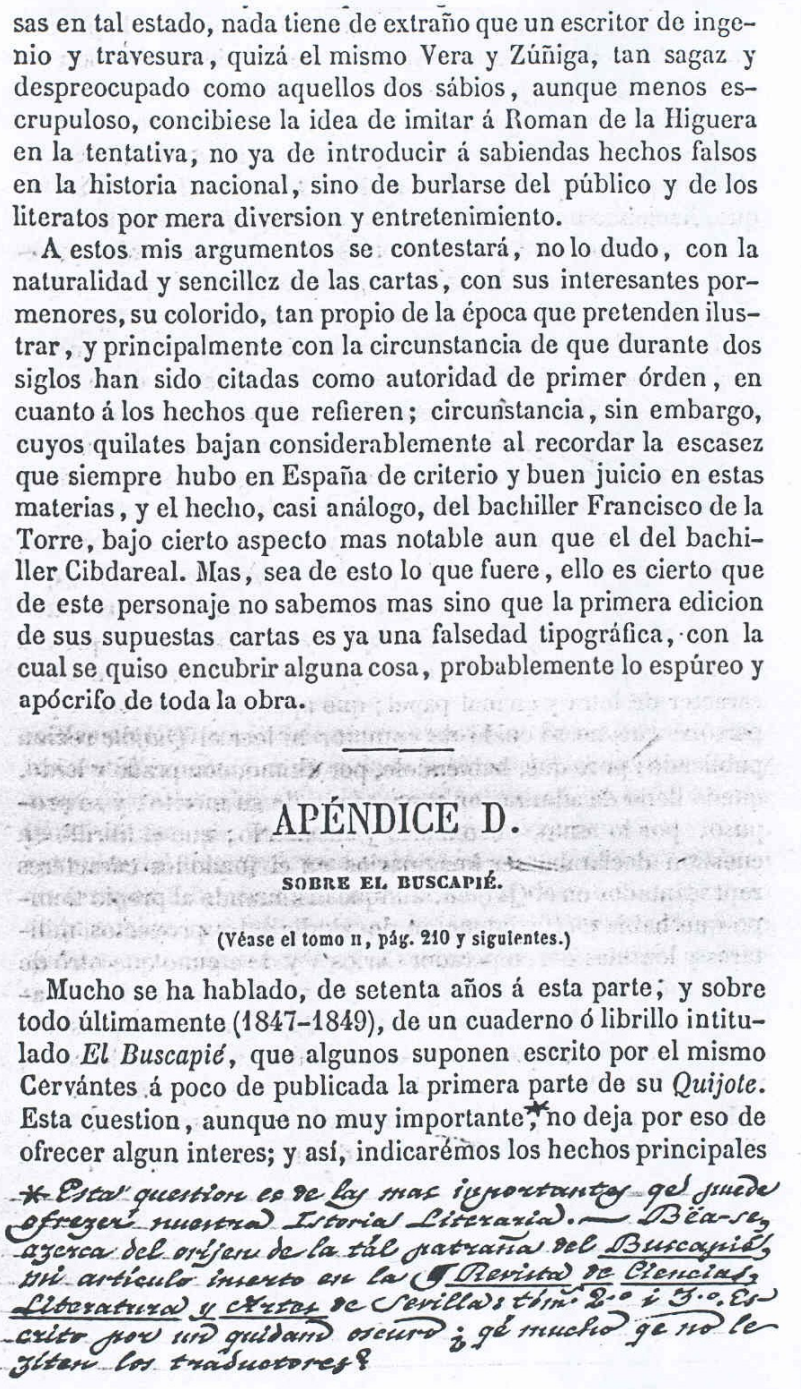

G. Ticknor, Historia de la literatura española, Rivadeneyra, Madrid, 1856, tomo IV, p. 207 Ejemplar de la Biblioteca Nacional de Madrid, sign. INV 860 Tic 